\title{
MENETELMÄ LAIDUNNURMEN KESKIMÄÄRÄISTÄ KASVUA KUVAAVAN KÄYRÄN LAATIMISEKSI
}

\author{
Tauno Laine \\ Laidunkoeasema, Mouhijärvi
}

Saapunut 20. 6. 1953 .

Satomäärien esittäminen laidunkokeista ei ole yhtä yksinkertainen tehtävä kuin muista peltoviljelykokeista, sillä kokonaissadon ohella olisi pyrittävä esittämään myös nurmen kasvussa esiintyvät vaihtelut, sen mukaan kuin ne eri sadonkorjuukertojen nojalla tulevat näkyviin. Kasvukäyrä on ilmeisesti luontevin nurmen kasvua ilmaiseva tapa, varsinkin jos sillä voidaan samalla kuvata sadon suuruutta. Kasvukäyrien laatimisen laidunnurmen kasvusta yhdeltä vuodelta on yksityiskohtaisesti esittänyt RAPPE (5). Kirjallisuudessa esitetään myös keskimääräisiä kasvukäyriä useammalta vuodelta $(1,2)$. Muunkinlaisia kuvaamistapoja esintyy, kuten pylväitä $(3,4)$, murtoviivoja (6) jne. Seuraavassa esitetään menetelmä, jossa keskimääräisen kasvun käyrällä pyritään kuvaamaan nurmen kasvua ja sadon suuruutta sekä niitettävistä että eläinryhmillä laidunnettavista kokeista pitäen lähtökohtana RAPPEn esittämää nurmen kasvun kuvaamistapaa.

\section{Niitettävän kokeen keskimääräistä kasvua osoittava käyrä}

Ryhdyttäessä laatimaan useamman vuoden keskimääräistä kasvua osoittavaa käyrää niittämällä korjatusta laidunkokeesta lasketaan ensin nurmen päivittäinen kasvu kunakin koevuonna siten kuin RAPPE on asian esittänyt: kullakin niitto-

Taulukko 1. Siemenseoskokeen —48 A-koejäsenen niittoajat, satomäärät ja päivittäinen kasvu 1949 —51

\begin{tabular}{|c|c|c|c|c|c|c|c|c|}
\hline & 1949 & & & 1950 & & & 1951 & \\
\hline $\begin{array}{l}\text { niitto- } \\
\text { aika }\end{array}$ & $\begin{array}{c}\text { kuiva-aine- } \\
\text { sato } \\
\mathrm{kg} / \mathrm{ha}\end{array}$ & $\begin{array}{c}\text { kasvu } \\
\text { kg/ha } \\
\text { päivässä }\end{array}$ & $\begin{array}{c}\text { niitto- } \\
\text { aika }\end{array}$ & $\begin{array}{c}\text { kuiva-aine- } \\
\text { sato } \\
\mathrm{kg} / \mathrm{ha}\end{array}$ & $\begin{array}{l}\text { kasvu } \\
\text { kg/ha } \\
\text { päivässä }\end{array}$ & $\begin{array}{l}\text { niitto- } \\
\text { aika }\end{array}$ & $\begin{array}{c}\text { kuiva-aine- } \\
\text { sato } \\
\mathrm{kg} / \mathrm{ha}\end{array}$ & $\begin{array}{c}\text { kasvu } \\
\text { kg/ha } \\
\text { päivässä }\end{array}$ \\
\hline $10 / 6$ & 2560 & 64 & $6 / 6$ & 762 & 21 & $20 / 6$ & 692 & 14 \\
\hline $7 / 7$ & 970 & 36 & $6 / 7$ & 1035 & 34 & $25 / 7$ & 916 & 26 \\
\hline \multirow[t]{2}{*}{$8 / 9$} & 1170 & 19 & $17 / 8$ & 706 & 17 & $11 / 9$ & 120 & 2 \\
\hline & & & $6 / 10$ & 180 & 4 & & & \\
\hline
\end{tabular}




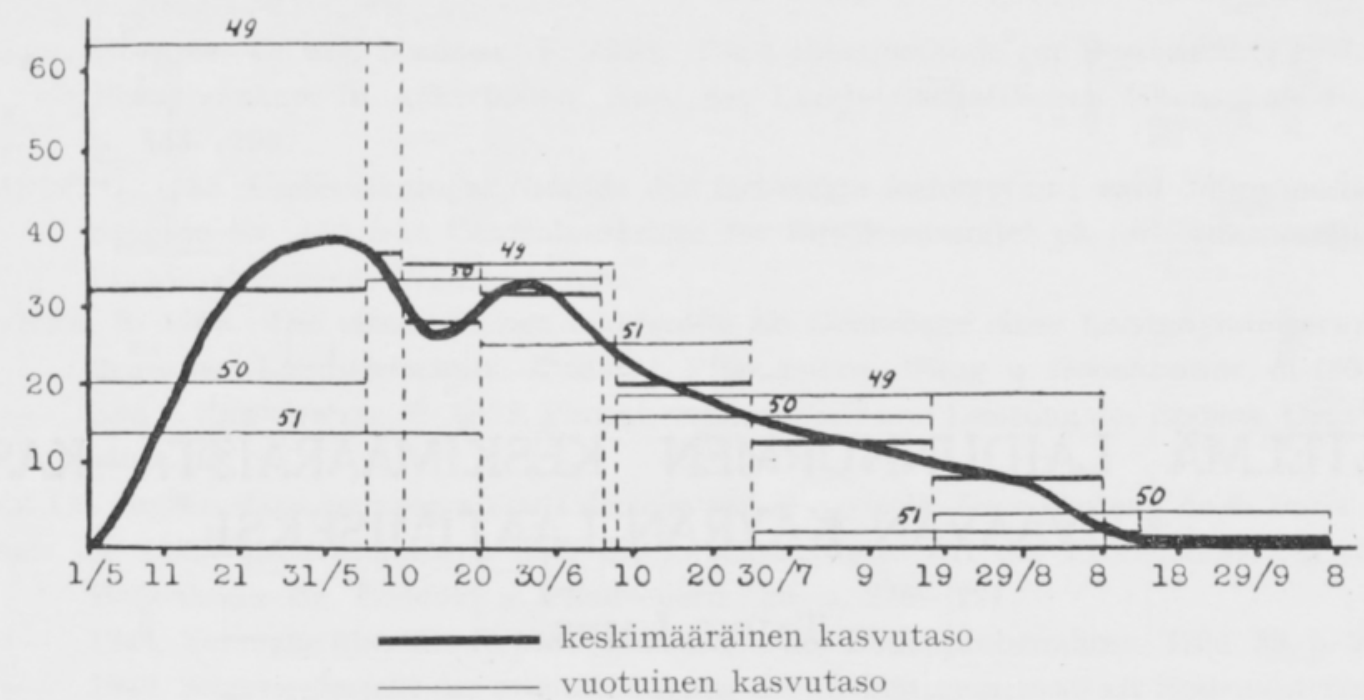

Piirros 1. Siemenseoskokeen -48 A-koejäsenen vuotuiset ja keskimääräiset kasvutasot sekä keskimääräisen kasvun käyrä.

kerralla saatu sato jaetaan edellisestä niittokerrasta kuluneiden päivien luvulla. Keväällä voidaan nurmien kasvun laskea Etelä-Suomessa alkavan toukokuun alussa, joten kevätkauden keskimääräinen päivittäinen kasvu saadaan jakamalla ensimmäisessä niitossa saatu sato toukokuun alusta nitttopäivään kuluneiden päivien luvulla. Esimerkkitapauksena esitetään taulukossa 1 erään laidunkoeasemalla suoritetun kokeen päivittäistä kasvua osoittavat arvot yhden koejäsenen osalta.

Kun päivittäistä kasvua osoittavat luvu+ määrätystä koejäsenestä on laskettu, merkitään ne piirroksessa 1 esitettyyn tapaan vaakasuorılla viivoilla kunkin koevuoden osalta suorakulmaiseen koordinaatistoon, jossa x-akselilla on aika keväästä syksyyn ja y-akseillla päıvittäinen kasvu. Näin saadaan koordinaatistoon niittoaikojen rajoittamia vaakatasoja, joita seuraavassa nimitetään vuotuisiksi kasvutasoiksi. Vuotuisten kasvutasojen perusteella piirretään tämän jälkeen keskimääräistä kasvua osoittavat tasot (keskikasvutasot) laskemalla kunkin nittovälin vuotuisten kasvutasojen keskiarvo. Esimerkkitapauksessa aikavälin 20/6-6/7 keskimääräinen kasvu on siten $(36+34+26): 3=32 \mathrm{~kg} / \mathrm{ha} \cdot \mathrm{p}$. Keskikasvutasoja saadaan näin menetellen yleensä yhtä monta kuin eri koevuosina on yhteensä ollut niittokertoja. Kun keskikasvutasot on piirretty koordinaatistoon, voidaan keskimääräistä kasvua osoittava käyrä piirtää keskikasvutasojen mukaan siten kuin RAPPE on asian esittänyt yhden kasvukauden osalta.

Keskikasvukäyrän tasoitus sekä käytännölliset laskems- ja piirtämismenetelmät

Laidunruohon kasvussa saattaa esiintyä huomattavaa vaihtelua kasvuedellytysten mukaan jo kahden toisiaan seuraavan niittokerran välillä. Nurmen kasvu ei siis ole käytännössä niin tasaista kuin vuotuisista kasvutasoista saattaisi päätellä. Vuotuisetkin kasvutasot ovat keskiarvoja eri niittokertojen välillä tapahtuneesta ruohon kasvusta. Koevuosien luvun kasvaessa tilapäisten sääsuhteiden vaikutus tasaantuu, mutta toisaalta eri vuosien yleissääsuhteet sekä usein myös kasvuston 


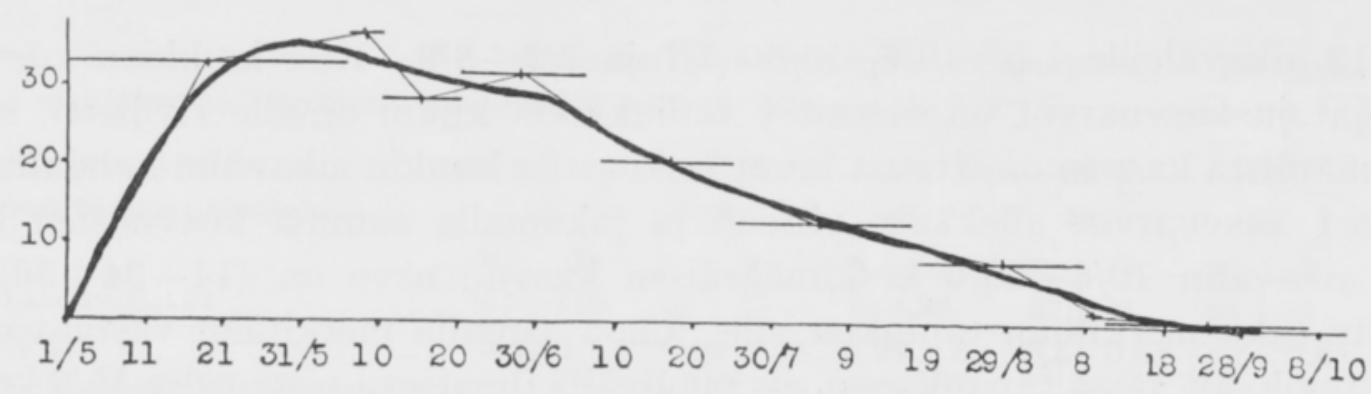

Piirros 2. Siemenseoskokeen —48 A-koejäsenen keskikasvutasot, niiden keskipisteitä yhdistävät janat ja janojen keskipistelinjaa seuraten piirretty, tasoitettu keskikasvukäyrä.

laadussa tapahtuvat muutokset saattavat aiheuttaa sen, että vuotuiset kasvutasot saattavat suuresti poiketa toisistaan, kuten piirrokseen 1 merkityistä kasvutasoista saattaa havaita. Keskikasvukäyrä saattaa tämän johdosta tulla melko mutkikkaaksi. Kun piirtämisessä olisi pyrittävä keskimääräisen kasvun yleissuuntaa noudattavaan linjaan, olisi käyrä pyrittävä tasoittamaan sopivin menetelnin. Yleispätevää sääntöä keskikasvukäyrän tasoittamiseksi on vaikea esittää, mutta yleensä voitaneen menetellä siten, että keskikasvutasojen keskipisteet yhdistetään janoilla piirroksessa 2 esitettyyn tapaan ja lopullinen käyrä piirretään noudattaen janojen keskipisteiden osoittamaa linjaa. Jos koevuosia on vähän ja niittoaikojen välit tästä johtuen verraten pitkiä, voidaan myös lyhyet, 1--5 päivän pituista aikaa vastaavat keskikasvutasot jättää keskikasvukäyrää piirrettäessä huomioonottamatta. Jos koevuosia on enemmän, tasoittuvat yksityisten vuosien aiheuttamat epäjohdonmukaisuudet, jolloin käyrän piirtäminen on verraten helppoa.

Jotta keskimääräistä kasvua osoittavan käyrän piirtäminen saataisiin mahdollisimman vähätöiseksi, on laskumenetelmien suorittamiseen ja käyrän piirtämistekniikkaan kiinnitettävä huomiota. Edelläesitettyä tasoitusmenetelmää käytettäessä tarvitsee koordinaatistoon merkitä ainoastaan keskikasvutasojen keskipisteet sekä näitä yhdistävät janat. Näin saadaan keväästä syksyyn vlottuva murtoviiva, joka osoittaa käyrän lopullisen suunnan. Keskimääräisen kasvun laskeminen eri niittoväleille tapahtunee käytännöllisimmin taulukossa 2 esitettyä menetelmää noudattaen. Taulukon kantaan merkitään ensin aikajaotus koko kasvukauden osalle. Tämän jälkeen merkitään kunkin koevuoden niittoajat kukin omalle rivilleen kannassa olevan aikajaotuksen mukaan. Kun satomäärä jaetaan edellisestä niitosta kuluneiden päivien luvulla, saadaan kunkin aikavälin päivittäinen kasvu, joka merkitään vastaavaan aikaväliin. Näin saadaan esim. vuodelle 1949 kasvuarvot 64,

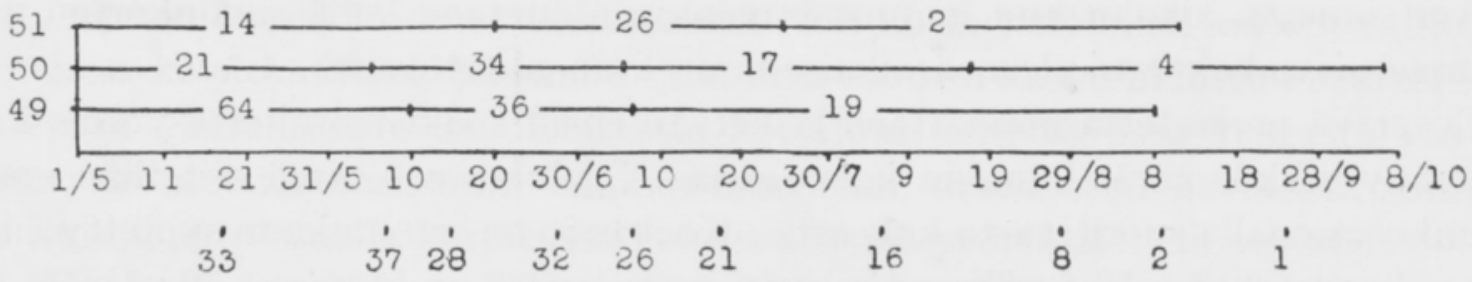

Taulukko 2.5 Siemenseoskokeen -48 A-koejäsenestä laadittu aikataulukko, johon on merkitty niittoajat eri vuosilta ja niittovälien päivittäinen kasvu. Taulukon alle on merkitty kunkin aikavälin keskipiste ja sen alle vastaavan aikavälin keskimääräinen kasvu. Esim. aikavälin 10/6-20/6 keskipiste on 15/6 kohdalla ja keskimääräinen kasvu $(14+34+36): 3=28)$. 
36 ja 19 aikaväleille $1 / 5-10 / 6,10 / 6-7 / 7$ ja $7 / 7-8 / 9$. Kun kaikkien koevuosien niittoajat ja kasvuarvot on merkitty taulukkoon kukin omalle rivilleen, saadaan keskimääräistä kasvua osoittavat luvut laskemalla kunkin aikavälin kohdalla olevat vuotuiset kasvuarvot allekkain yhteen ja jakamalla summa koevuosien luvulla. Esim. aikavälin 10/6-20/6 keskimääräisen kasvun arvo on $(14+34+36): 3=28$. Mainittu luku merkitään taulukon alle, johon samalla merkitään vastaavan aikajakson puoliväli, tässä tapauksessa siis puoliväliä ilmaiseva piste tulee $15 / 6$ kohdalle. Sen alle merkitään luku 28. Taulukon alla olevat pisteet ja lukuarvot merkitään koordinaatistoon, jolloin piste ilmaisee aikamäärän ja lukuarvo pisteen korkeuden. Pisteiden kautta piirretty murtoviiva on silloin pohjana lopullista keskimääräistä kasvua osoittavaa käyrää piirrettäessä. Käytännössä on paras laatia aikataulukko ruudulliselle paperille ja piirtää keskikasvukäyrä samalle arkille aikataulukon alle. Jokaisesta koejäsenestä laaditaan aikataulukko ja keskikasvukäyrä erikseen, minkä jälkeen kaikkien koejäsenten keskikasvukäyrät yhdistetään samaan koordinaatistoon, kuten piirroksessa 3 on esitetty.

\section{Eläinryhmillä laidunnetun kokeen keskikasvukäyrä}

Nurmen kasvussa esiintyvàt vaihtelut on niitettävästä laidunkokeesta verraten helppoa esittää ilman keskikasvukäyriäkin. Eläinryhmillä laidunnetusta kokeesta tämä on vaikeampaa, joten keskikasvukäyrä tällaisesta kokeesta on vielä tärkeämpi kuin niitettävästä kokeesta edellyttäen, että keskikasvukäyrä voidaan laatia nurmen hyväksikäyttöä vastaavaksi. Kun koetta laidunnetaan koeryhmillä usein yhtämittaisesti keväästä syksyyn eläinlukua nurmen kasvun mukaan muuttamalla, on laidunkausi jaettava lyhyempiin ajanjaksoihin, jotta käyrän laatiminen yleensä olisi mahdollista. Laidunnettavissa kokeissa noudatetaan koealueen jaossa samaa periaatetta kuin niitettävissäkin kokeissa: koealue jaetaan koejäseniä vastaaviin useampilohkoisiin koekiertoihin, joista kukin syötetään omalla eläinryhmällään. Koekierron kertasyöttöön kulunutta aikaa voitaneen tällöin pitää aikajaottelun pohjana keskikasvukäyrää laadittaessa. Jos koeryhmä on ollut koekentältä välillä poissa, lasketaan väliaika kuuluvaksi sitä seuraavaan kierron syöttöaikaan. Jos nurmen kasvu on nopeaa ja kierron syöttöaika tästä syystä lyhyt, voitaneen perusajanjaksona käyttää aikaa, joka on kulunut kierron syöttämiseen kahteen kertaan. Näin voidaan menetellä erityisesti keski- ja loppukesällä, jolloin nurmen kasvu yleensä on tasaisempaa kuin keväällä. Nurmen kasvun voidaan keväällä laskea alkavan samaan aikaan kun laiduntaminenkin aloitetaan, sillä sadonkorjuu alkaa laidunnetuissa kokeissa yleensä aikaisemmin kuin niitettävissä.

Esitettyä periaatetta noudattaen lasketaan ensin koekierron kertasyötöissä saadut rehuyksikkömäärät kunakin koevuonna. Taulukossa 3 tämä esitetään eräästä laidunkoeasemalla suoritetusta kokeesta. Koekierto on sen mukaan syötetty ensimmäisen kerran 30/5-18/6 välisenä aikana, joten syöttö on kestänyt 19 päivää. Laidunpäiviä on tänä aikana tullut uuhille 97 ja karitsoille 110 . Kun nämä on kerrottu eläinten päivittäin kuluttamalla rehuyksikkömäärällä $(0,99$ ja 1,13$)$, on eläinten käyttämäksi rehuyksikkömääräksi saatu $96+124=220$. Mainittu luku jaetaan koekier- 
Taulukko 3. Siemenseoskokeen - 35 A-kierron kertasyöttöön kuluneet ajanjaksot v. 1941 sekä koeryhmän näinä ajanjaksoina käyttämät rehuyksikkömäärät. Kierron ala $0.307 \mathrm{ha}, \mathrm{u}=\mathrm{uuhet}$, $\mathrm{k}=\mathrm{karitsat}$

\begin{tabular}{|c|c|c|c|c|c|}
\hline $\begin{array}{l}\text { Kierron syöttöajat. ....... } \\
\text { Syöttöajan päiväluku }{ }^{1} \text { ) . . . }\end{array}$ & $\begin{array}{c}30 / 5-18 / 6 \\
19\end{array}$ & $\begin{array}{c}-27 / 6 \\
9\end{array}$ & $\begin{array}{c}-13 / 7 \\
16\end{array}$ & $\begin{array}{l}-23 / 8 \\
41\end{array}$ & $\begin{array}{c}-109 \\
18\end{array}$ \\
\hline & $\mathrm{u} \quad \mathrm{k}$ & $\mathrm{k}$ & $\mathrm{u} \quad \mathrm{k}$ & $\mathrm{u}$ & $\mathrm{k}$ \\
\hline Laidunpäivät . . . . . . . . . . & $97+110$ & $36+27$ & $48+36$ & $52+26$ & $64+30$ \\
\hline $\begin{array}{l}\text { ry } / \text { lp. } \ldots \ldots \ldots \ldots \ldots \ldots \ldots \\
\text { ry kierron syöttöaikana }\end{array}$ & $0.99 \quad 1.13$ & 0.990 .68 & 0.990 .68 & $0.54 \quad 0.62$ & $0.54 \quad 0.62$ \\
\hline uuhet...$\ldots \ldots \ldots$. & 96 & 36 & 48 & 28 & 35 \\
\hline karitsat $\ldots \ldots \ldots \ldots$ & 124 & 18 & 24 & 16 & 19 \\
\hline Yht. ry $\ldots \ldots \ldots \ldots \ldots$ & 220 & 54 & 72 & 44 & 54 \\
\hline Kasvu ry/ha.p ........ & 38 & 20 & 15 & 3 & 10 \\
\hline
\end{tabular}

1) Koeryhmä on osan ajasta $13 / 7-23 / 8$ ollut poissa koekentältä.

ron pinta-alalla ja syöttöajan päiväluvulla, jolloin päivittäiseksi kasvuksi saadaan 38 ry hehtaaria kohti. Näin menetellen saadaan päivittäiset kasvuarvot koko kesälle sekä eri koevuosille, minkä jälkeen vuotuiset kasvuarvot yhdistetään aikataulukkoon samaan tapaan kuin taulukossa 2 on esitetty niitettävän kokeen osalta. Lopullinen keskikasvukäyrä laaditaan sitten samaan tapaan kuin niitettävästäkin laidunkokeesta.

\section{Keskikasvukäyrillä saatavien tulosten tarkastelua}

Laidunkoeasemalla saatujen kokemusten mukaan keskikasvukäyrät antavat helposti käsitettävän yleiskuvan laidunkokeiden tuloksista sekä eräistä niıhin vaikuttaneista tekijöistä. Paitsi nurmen kasvussa esiintyviä eroja käyrät ilmaisevat myös sadon suuruuden, jota kuvaa käyrän ja x-akselin rajoittama ala. Mitä korkeampi keskikasvukäyrä on, sitä suurempi on myös sato edellyttäen, että käyrän ja $\mathrm{x}$-akselin rajoittama ala on sama kuin keskimääräisten kasvutasojen ja x-akselin rajoittama ala. Suurin virhe näiden alojen suhteessa esiintyy niitettävän kokeen keskikasvukäyrän alkuosassa, ja virhe muodostuu sitä suuremmaksi, mitä myöhäisemmällä asteella ensimmäinen niitto on suoritettu. Kun keskikasvukäyrä piirretään esitettyä menettelyä noudattaen, jää nurmen sato n. $10 \%$ pienemmäksi, kuin se niittojen mukaan on ollut. Käyrän piirtäminen esitettyyn tapaan johtuu siitä, että se vastaa tällöin paremmin laidunnetun kokeen keskikasvukäyrän muotoa. Kun virhe on kaikilla koejäsenillä samaa suuruusluokkaa, ei sillä ole käytännöllistä merkitystä koejäseniä toisiinsa verrattaessa. Eri koemenetelmien kesken vallitseva ero nurmen kevätkasvussa johtunee siitä, että nurmen kasvu hidastuu suuresti, jos se niitetään nuorella asteella. Kun sato korjataan niitettävästä kokeesta yleensä nurmen saavutettua normaalin laiduntamisasteen, muodostuu kevätsato suuremmaksi kuin laiduntamalla korjatussa kokeessa, jossa syöttö aletaan varhain.

Laidunnettavan kokeen kasvuarvoissa saattaa edellä esitetyn tavan mukaan laskien esiintyä epäjohdonmukaista vaihtelua enemmän kuin niitettävissä kokeissa. Laidunnurmen syöttöä on nimittäin vaikea saada seuraamaan kasvussa esiintyviä vaihteluja, mistä johtuen ruohoa pääsee toisinaan kasvamaan varastoon, toisinaan 


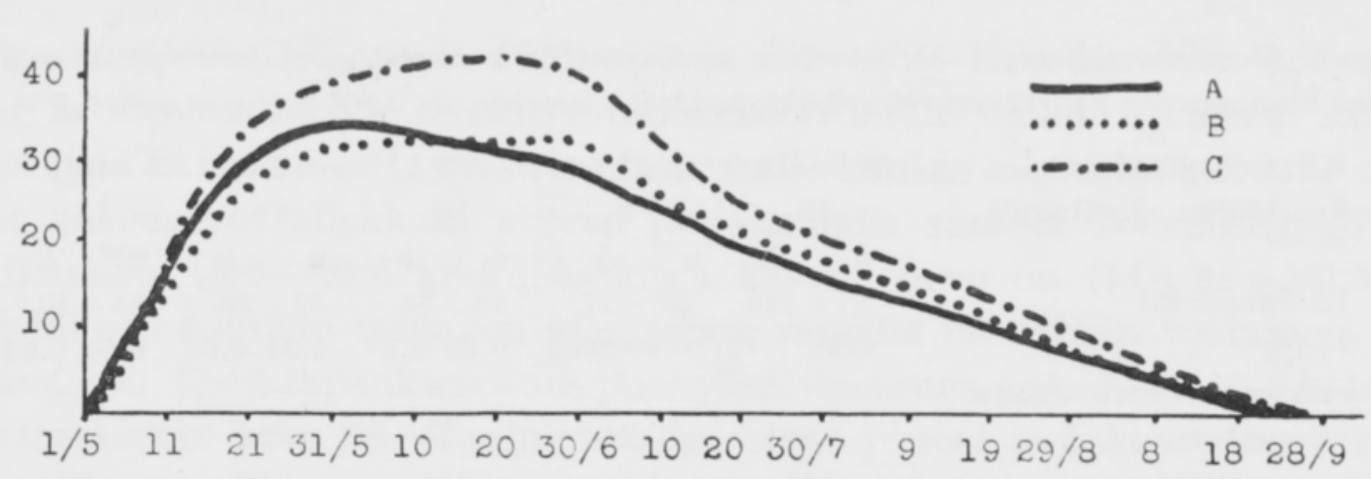

Piirros 3. Siemenseoskokeen -48 keskikasvukäyrät v. $1949-51 . \mathrm{A}=$ monipuolinen siemenseos, $\mathrm{B}=$ nurminatavaltainen seos, $\mathrm{C}=$ koiranruohovaltainen seos. Kuiva-aineen keskisadot $\mathrm{A} 3034 \mathrm{~kg} / \mathrm{ha}$, B $3112 \mathrm{~kg} /$ ha ja C $3860 \mathrm{~kg} / \mathrm{ha}$.

taas nurmen hyväksikäyttö on nopeampaa kuin sen kasvu. Erityisesti suurehkojen vararyhmien käyttö varastoon kasvaneen ruohon talteenotossa saattaa aiheuttaa huomattavia poikkeamia keskiarvoista. Koevuosien luvun lisääntyessä tällaiset poikkeamat kuitenkin tasaantuvat. Laidunnettavan kokeen keskikasvukäyrän vo1daan joka tapauksessa katsoa vastaavan käytännön laiduntaloudessa esiintyviä olosuhteita.

Esimerkkinä niitettävän kokeen keskikasvukäyristä esitetään piirroksessa 3 laidunkoeasemalla v. 1948 perustetun siemenseoskokeen keskikasvukäyrät vuosilta 1949-51. Käyrä A esittää monipuolisen siemenseoksen, B nurminatavaltaisen ja C koiranruohovaltaisen siemenseoksen keskikasvua hiesusavimaalla. Käyristä toteamme ensiksikin, että koiranruohovaltainen nurmi on antanut suurimmat sadot. Nurmen kasvu on keväällä ollut nopeampaa kuin muilla seoksilla kylvettyjen nurmien, mınkä lisäksi jälkikasvu heinäkuun puoliväliin saakka on ollut hyvän joukon parempi. Nurminatavaltaisen nurmen kasvu on keväällä ollut hitaampaa, mutta keski- ja loppukesällä parempi kuin monipuolisella siemenseoksella kylvetyn nurmen. Samat seikat on todettavissa eri niittokerroilla saaduista sadoista, mutta keskikasvukäyrät antavat niistä hyvän yleiskuvan.

Piirroksessa 4 esitetään v. 1935 perustetun siemenseoskokeen keskikasvukäyrät vuosilta 1941—43. Koe sijaitsi hiesusavimaalla ja laidunnettiin lammasryhmillä. Käyrä A esittạä monipuolisen siemenseoksen, B nurminatavaltaisen ja C nurmipuntarpäävaltaisen nurmen keskimääräistä kasvua. Koko koeajan 1936-43 keskisadoissa ja keskikasvukäyrissä ei ollut mainittavia eroja. Puntarpäävaltainen seos antoi kuitenkin hieman paremman keskisadon kuin muut, minkä aluksi oletettiin aiheutuvan joistakin koevirheistä. Loppuvuosien keskikasvukäyrät osoittavat kuitenkin selvästi, että satoerot ovat johtuneet nurmipuntarpään nopeammasta kasvusta keväisin. Nurminatavaltaisen nurmen kasvu on tässäkin kokeessa ollut keväällä hitaampaa kuin muiden koekiertojen eikä loppukesälläkään monipuolisella siemenseoksella kylvetyn nurmen kasvua parempi. Poutaisista koevuosista ja vähäisestä typpilannoituksesta johtuen nurmien kasvu on ollut muutenkin heikonlainen ja sadot jääneet pieniksi.

Esitetyt pari esimerkkiä osoittavat, että keskikasvukäyrät antavat tarkoitustaan vastaavan yleiskuvan laidunkokeista sekä eräistä satomääriin vaikuttaneista 


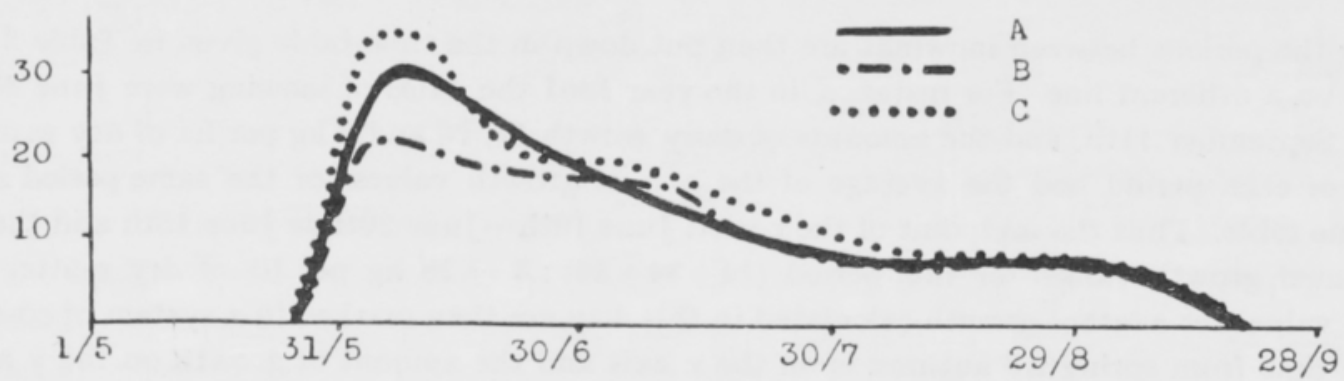

Piirros 4. Siemenseoskokeen -35 keskikasvukäyrät v. 1941—43. A $=$ monipuolinen siemenseos, $\mathrm{B}=$ nurminatavaltainen seos, $\mathrm{C}=$ nurmipuntarpäävaltainen seos. Keskisadot 1941 -43 A 1552 ry/ha, B 1315 ry/ha, C 1845 ry/ha.

tekijöistä. Koevuosien sääsuhteet, kasvustossa tapahtuvat muutokset ym. seikat saattavat yksityisten vuosien kasvukäyrissä aiheuttaa huomattavia poikkeamia toisistaan, mutta keskikasvukäyrä esittää kuitenkin lyhyesti sen, mikä numerollisesti esitettynä vaatii enemmän tilaa ja erityisesti laidunnetuista kokeista on yleensä vaikeasti esitettävissä.

KIR J ALLISUUSLUETTELO

(1) Borg, JoH. 1929, Något om möjligheterna att genom indelning av betesmarker reglera tillgången på bete. Svenska Betes- och Vallföreningens Årsskrift 1929, p. $197-218$.

(2) GıöBEL, G. 1945. Betestillväxtens säsongvariation. Några resultat från föreningens betesförsök. Svenska Vall- och Mosskulturföreningens kvartalskrift N:o 4, 1945, p. 298-316.

(3) Johnstone-Wallace, D. B. 1934. The Improvement and Management of Permanent Pastures. Cornell University Agr. Exp. Sta. Bull. 612, p. 35-77.

(4) Nevens, W. B. 1944. Improving Bluegras Pastures. University of Illinois Agric. Exp. Sta., Bull. 504.

(5) Rappe, Gerhard, 1946. Grafisk framställning av betestillväxt och väderlek. Svenska Vall- och Mosskulturföreningens meddel. 13. Norrtälje.

(6) Welton, F. A. ja Carrol, J. C. 1940. Lawn Experiments. Ohio Agr. Exp. Sta., Bull. 612.

\section{S U M M A R Y}

A METHOD OF DRAWING A CURVE DESCRIBING THE AVERAGE GROWTH OF PASTURE GRASS

TAUNO LAINE

Pasture Experimental Station, Tohmajärvi

The paper presents a method of drawing a curve describing the average growth of grass in pastures on the basis of pasture experiments extending over several years. The starting point is RAPPE's (5) method of drawing a growth curve for one growth period. Where the experimental plots are to be mown, the daily growth of the grass is first calculated for each experimental year separately, as RAPPE has described (the yield divided by the number of days passed since the previous mowing). The growth 
values for the periods between mowings are then put down in the time-table given in Table 2 (p. 187), each year on a different line. For instance, in the year 1951 the dates of mowing were June 20th, July $25 \mathrm{th}$, and September $11 \mathrm{th}$, and the amounts of daily growth 14,26 and $2 \mathrm{~kg}$ per ha of dry matter. The midpoint of each period and the average of the annual growth values for the same period are giwen beneath the table. Thus the midpoint of the period June 10th-June 20 th is June 15 th and the average of the annual growth values for this-period $(14+34+36): 3=28 \mathrm{~kg}$ per ha of dry matter per day.

The values for average growth calculated in this way are then marked in a system of co-ordinates where the time from spring till autumn is on the $\mathrm{x}$ axis and the amount of growth on the $\mathrm{y}$ axis. The points are joined by straight lines, and the final growth curve is drawn along the line indicated by the midpoints of the lines. This method of drawing the curve aims at modifying the irregularities caused by occasional factors. This method was used in Figure 2 (p. 187), which also gives levels showing the average growth for different periods. The curve of average growth is drawn separately for each member of the experiment, and finally added to the same system of co-ordinates in the way shown in Figure 3 (p. 190). As the space limited by the curve of average growth and the $\mathrm{x}$ axis represents the total yield of the growth period, the curve indicates both the amount of yield and the average changes in growth occurring during the growth period. In the case reported, growth is assumed to have begun at the beginning of May in the different years.

The curve of average growth for experimental plots grazed with livestock is drawn in a similar way, except that the time representing the periods between different mowings is the period needed for grazing the pasture once and the number of fodder units received by the animals during this period. If, at any time, the animals were not grazing in the pasture, the interval was included in the next period of grazing. The growth period is supposed to have begun when the animals are put out to grass in spring. Figure 4 (p. 191) gives the curves of average growth for an experimental plot grazed with sheep. 